\title{
Calculation of Free Convection Influence on the Response of Heat Flux Meters
}

\author{
BROR PERSSON and MARGARET SIMONSON \\ Swedish National Testing and Research Institute (SP) \\ Box 857, S-501 15 Borås, Sweden
}

\begin{abstract}
ABS TRACT
Radiometers or heat flux meters used in fire testing are frequently mounted in free air in front of flames or furnaces and thus measure the total heat flux i.e. both radiation and convection. If the gages are calibrated in a pure radiative environment then corrections are needed for the convective influence. Other applications are in flammability test methods where the precise measurement of incident radiant flux is important. Again corrections for the convective influence is necessary. At low heat fluxes even the free convection induced by the sensor itself can cause substantial errors. A sensor mounted flush in an exposed specimen will be influenced by the convection induced by the hot surface of the specimen.
\end{abstract}

The present paper demonstrates the feasibility of using CFD (Computational Fluid Dynamics) calculations as a tool in achieving corrections to recorded heat fluxes due to the influence of convection. The CFD code SOFIE has been used to compute the heat transfer caused by free convection for a Schmidt-Boelter gage, and the calculated corrections have been compared to experimental data. Two cas es have been investigated, a sensor in free air with the cooling water different from the temperature of the surrounding air, and a sensor mounted in a heated refractory board. Predicted heat transfer coefficients are in sufficient agreement with previous measurements published by Roberts on and Ohlemiller [1] to confirm the utility of the approach.

KEYWORDS : CFD, Numerical Analysis, Convection, Radiation Heat Flux, Gages

\section{INTRODU CTION}

Heat flux meters are widely used in fire research and fire testing. Traditionally, heat flux data has been used mainly for research purposes but more recently heat flux meters have become important as calibration and measuring devices in the new generation of reaction to fire standard testing methods. In many applications the experimental heat flux results are treated as an absolute. Little concession is made to any uncertainty in the experimental measurements and, in some cases, little effort is made to minimise this uncertainty. This problem is particularly difficult in fire safety testing due to the inherent complexity of fires. 
In the fire community there are two main methods in use for the calibration of heat flux gages. One method is the so called direct 'closed' method which uses a furnace radiation source with the radiometer inserted into the radiation cavity through an aperture. Thus the radiometer is subjected to both convective and radiative heat transfer. The convective effects can only be neglected for very high flux levels (above $100 \mathrm{~kW} / \mathrm{m}^{2}$ ) and substantial errors can result. This method is only really useful when the application environment closely mimics the calibration set-up.

The other method, which is decidedly more complicated, is the so called 'transfer' method. In this method a primary standard calorimeter is used up to $60 \mathrm{~kW} / \mathrm{m}^{2}$. This value is then compared to a secondary standard subjected to the same source. It is this secondary standard that is then used in the direct calibration of the actual radiometer, i.e., the primary standard is not used directly. Due to the complexity of this calibration method, with several steps which all contain a certain degree of error, great care must be taken at all times to minimise the uncertainties. Furthermore it is difficult to quantify the error incorporated into the calibration.

It is recognised that convective effects may have a strong influence on both the use [1] and calibration [2,3] of heat flux meters and methods have been developed to diminish the effect of convection in calibration. One method which has been developed in our laboratory is a modification of the direct closed calibration method described above [2,3]. The insertion of the probe is arranged such that the gage is not in direct contact with the hot surface gas and this set-up is referred to as 'semiclosed'. This configuration is so constructed as to minimise convection effects. Another method which has come into use is based on the complete elimination of convective influences i.e. calibration in vacuum (pressure $1 \mathrm{~Pa}$ ). Such a calibration device has been developed by LNE (Laboratorie National d'Essais) in France.

The fidelity of a calibration is, however, highest when the application environment closely mimics the calibration environment. In all cases where there is a significant divergence between these two environments the potential for systematic errors increases, which can lead to a large increase in the uncertainty of the measurements. As explained above calibration of radiative heat flux sensors typically occurs under conditions that have been contrived to minimise convective effects. Experimental measurements incorporating a mixed heat flow regime (as is typically the case) contain a convective contribution to the total heat flux which must, therefore, be corrected for before the radiative calibration can be assumed valid. As it is not tractable to calibrate all heat flux meters in all pos sible end-use configurations some reliable method for estimating this convection contribution is neces sary.

Due to their widespread commercial availability and ease of application the most common heat flux meters in fire safety testing are the Gardon gage and the SchmidtBoelter gage, both named after their developers [2]. The Gardon gage uses a differential thermocouple design where the heat flux is measured as a function of the difference in the temperature between the center of the measurement cell, a metal foil, and its peripheral bound with the water-cooled gage housing. The Schmidt-Boelter gage is of thermopile design with the signal resulting from the development of a temperature difference across a thin region of thermally stable material situated between the sensing surface and the water-cooled gage body. These two diverse measurement techniques present different problems in terms of sensitivity to measurement conditions but both suffer from widespread calibration in radiative environments coupled to use in mixed heat flux regimes.

The problem of correcting heat flux measurements for convection effects has been investigated in [4] for Gardon gages. The advised corrections rest on the assumption that the heat transfer coefficients are known for the convective exchange between the 
surroundings and the measurement cell. The same approach can be adopted for $\mathrm{S}$ chmidt-B oelter gages. In this case the corrections are even simpler to perform due to the more even temperature distribution of the sensing element of this gage. How ever, to enable such corrections in practice, methods must be found to obtain accurate estimates of these heat transfer coefficients (or the convective heat flux contribution explicitly) under the relevant measurement configurations. Again detailed experimental determination of these heat transfer coefficients for all possible situations is hardly a tractable problem and some reliable theoretical or computation method is desired.

In this paper it is demonstrated that Computational Fluid Dynamics (CFD) calculations provide such a tool. Through a comparison between CFD and experimental estimates of heat transfer coefficients and heat fluxes we have been able to establish the potential of such computational methods for these applications.

\section{A STRATEGY FOR CALIBRATION AND USE OF HEAT FLUX METERS}

Within EGOLF (European Group of Official Laboratories for Fire Testing) a decision has been taken to construct guidelines for the calibration and use of heat flux meters for fire testing. A primary calibration procedure is to be selected giving a primary reference calibration. This primary calibration will be carried out at a specific laboratory selected for keeping the primary standard. Based on this primary calibration, secondary and tertiary calibrations will then be performed at each laboratory and compared between different laboratories. Convection may influence both the calibration and application of these gages and thus methods must be developed to determine the neces sary correction factors at each step.

The present work demonstrates a possible approach to obtain corrections for convection effects when using heat flux gages. The theoretical work should be supplemented by carefully conducted experiments to verify the selected approach of applying correction factors. In these experiments surface temperatures of the sensing element and of all surrounding surfaces should be measured. This data will provide the necessary input to the CFD calculations. These experiments have not yet been conducted and the present paper deals with the theoretical part of this work. Support for the present approach is, however, obtained by making use of experimental results recently published in the literature.

\section{COMPUTATIONS}

Numerical calculations of the free convection current induced by the heated sensing element of a Schmidt-Boelter gage have been carried out and the convective influence of a heated backing has been investigated. The calculations have been performed with the CFD code SOFIE [5]. This is a new code developed especially for fire and combustion applications although it can be used for conventional fluid dynamics problems.

The computational domain is shown schematically in Figure 1 with the sensing surface of the gage oriented vertically. The case shown in Figure 1 corresponds to a gage mounted in a wall and protruding a distance $s$ out of the wall (only the case $s=0$ will be treated here). The temperature of the wall is denoted $T_{w}$, that of the surfaces of the gage $T_{c}$, and that of the sensing element is $T_{s}$. Ambient temperature is denoted by $T_{a}$. The computational domain is arranged as a rectangular box with dimensions 
$155 \mathrm{~mm} \times 80 \mathrm{~mm} \times 130 \mathrm{~mm}$ in the $x, y$, and $z$ directions with the $x$-axis defined as being directed upwards. Due to symmetry only half of the domain in the $z$-direction is included in the calculations.

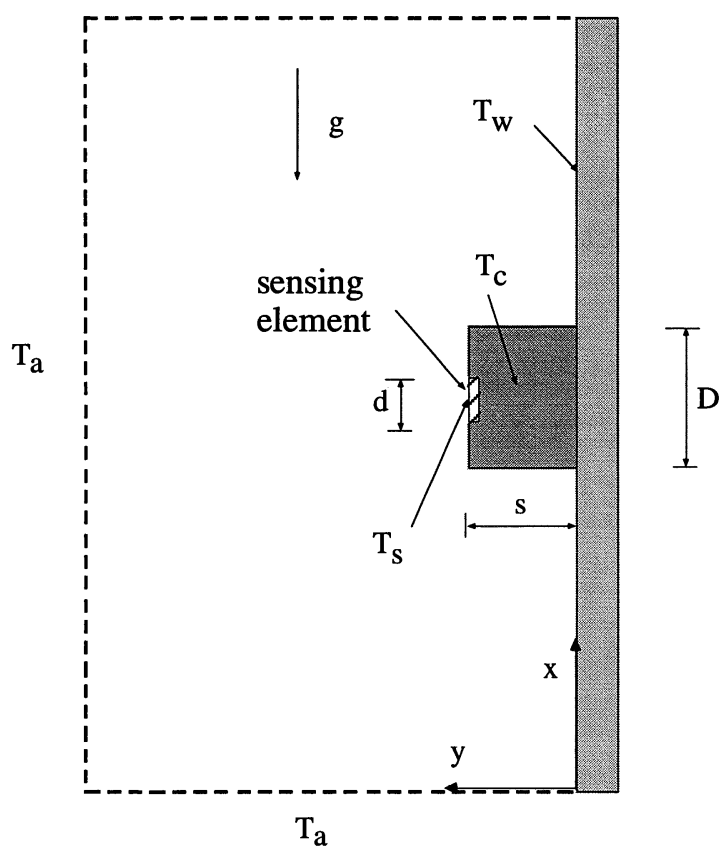

FIGURE 1: Schematic diagram of the computational domain.

The numerical grids used for the simulations are indicated in Figure 2 together with the boundary conditions. The grid system $w$ as varied smoothly in all directions $w$ ith a minimum step size close to the solid wall and the surfaces of the gage. To investigate the influence of the grid size different mesh sizes were used varying between 100000 to 200000 cells. The difference in computed results were less than $10 \%$ between these two mesh sizes. In the case with 205000 cells $(85 \times 59 \times 41)$ the minimum step size was $0.3 \mathrm{~mm}$ increas ing to about $4 \mathrm{~mm}$ close the boundaries. All solid surfaces were described as isothermal surfaces in the calculations, Figure 2. The Boussinesq approximation was adopted in calculating the buoyancy forces and the properties of air were assumed constant.

Two different cas es have been considered. These were chosen due to the availability of experimental data for verification of the calculations and because they correspond to two fundamentally different applications of heat flux meters. The first case is a gage surrounded by free air while the second case treats a gage mounted flush with the heated surface of a refractory board. In the case of the gage suspended in free air the backing wall indicated in Figures $1-2$ is replaced by a constant pressure boundary in the calculations. 
The heated element in the gage is defined as a square sensor with dimensions $5 \mathrm{~mm} \times$ $5 \mathrm{~mm}$. This configuration simulates a sensor with a diameter of $d=5 \mathrm{~mm}$ in the flow direction. The sensor is surrounded by a cooled isothermal surface extending $10 \mathrm{~mm}$ in all directions, i.e., with dimensions of $25 \mathrm{~mm} \times 25 \mathrm{~mm}$ with the sensor located in the center of this housing. This simulates a gage with an external diameter of $D=25$ $\mathrm{mm}$. These dimen sions have been chosen as they are typical of most Schmidt-Boelter gages presently in use in fire applications.

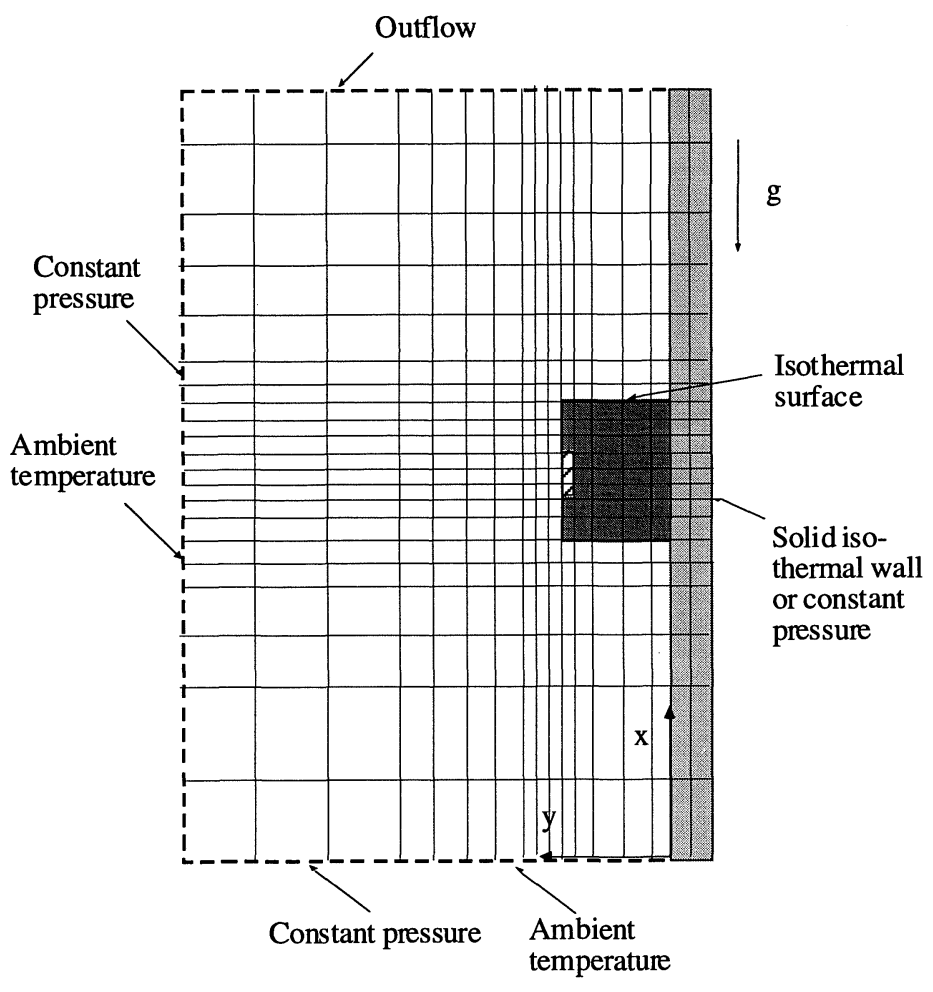

FIG URE 2: Numerical grid distribution and boundary conditions.

The gage is located symmetrically in the vertical surface of the calculation domain. The temperature of the sensing element, $T_{s}$, is slightly different from the temperature of the surrounding surfaces, depending on the flux. In the case of the sensor suspended in free air an estimation of the temperature of the sensor yielded a negligible difference from that of the cooling water, $T_{c}$. Thus, in these calculations the temperature of the sensor was set to that of the cooling water. In the case of the 
gage mounted in the refractory board the sensor was estimated to have a temperature approximately $5{ }^{\circ} \mathrm{C}$ above that of the cooling water. Both estimates were based on the assumption that the thermopile sensor had 32 junctions.

In order to perform the calculations for the case with the sensor mounted in a refractory board one requires information concerning the temperature of the board, $T_{w}$. Measurements in the radiant panel configuration (ISO 9239) indicate that for a heat flux of $8 \mathrm{~kW} / \mathrm{m}^{2}$ the temperature of the refractory board $\left(T_{w}\right)$ is approximately $250^{\circ} \mathrm{C}$. This figure is uncertain and calculations have therefore been performed also with $T_{w}=$ $230^{\circ} \mathrm{C}$ to get an indication of the dependence on the backing wall temperature.

\section{RES ULTS AND DIS CUSSION}

A number of interesting experimental results concerning the influence of convection on measurements with Schmidt-Boelter gages have been reported by Roberts on and Ohlemiller [1]. In one of the experiments (Case 1 in Table 1) the effect of the cooling water temperature was investigated by exposing the gage to the surrounding air and varying the water temperature. For a meter rated at

$10 \mathrm{~kW} / \mathrm{m}^{2}$ they obtained a signal of $+0.20 \mathrm{mV}$ for a cooling water temperature of $12^{\circ} \mathrm{C}$ and $-0.40 \mathrm{mV}$ at $+46^{\circ} \mathrm{C}$. Other measurements indicate a calibration constant of $1.255 \mathrm{~kW} / \mathrm{m}^{2} \mathrm{mV}$ for this gage. Thus the measured signals correspond to a heat flux of 250 and $500 \mathrm{~W} / \mathrm{m}^{2}$, respectively.

Assuming that the sensing area of the gage suspended in free air has almost the same temperature as the cooling water, heat balances for the two cases with different cooling water temperatures can be formulated. A system of two equations with two unknowns, i.e., the heat transfer coefficient and the ambient temperature, is thereby constructed. This calculation indicates a heat transfer coefficient of approximately 16 $\mathrm{W} / \mathrm{m}^{2} \mathrm{~K}$ and an ambient temperature of approximately $24^{\circ} \mathrm{C}$ for this configuration. This means that approximately $70 \%$ of the heat flux is due to convection i.e. 175 and $350 \mathrm{~W} / \mathrm{m}^{2}$, respectively.

Applying these values for $T_{s}$ and $T_{a}$ in the calculations and assuming that all surfaces of the gage, except the sensing element, are at the ambient temperature $\left(T_{c}=T_{a}\right)$ yield a heat transfer coefficient of $20 \mathrm{~W} / \mathrm{m}^{2} \mathrm{~K}$ which is about $25 \%$ higher than the value estimated from the experimental results. If one instead assumes that the cylindrical surface of the gage has a temperature equal to the cooling water temperature temperature $\left(T_{c}=T_{s}\right)$ the heat transfer coefficient is reduced to $7 \mathrm{~W} / \mathrm{m}^{2} \mathrm{~K}$. Using these calculated values for the heat transfer coefficient, the heat flux can be estimated to be in the range $90-240 \mathrm{~W} / \mathrm{m}^{2}$ for $T_{c}=12^{\circ} \mathrm{C}$ and $160-440 \mathrm{~W} / \mathrm{m}^{2}$ for $T_{c}=46^{\circ} \mathrm{C}$. These results are in close agreement with the experimental results and are summarised in Table 1. The results clearly indicate the strong dependence upon the boundary conditions. Also shown in Table 1 are the results for the configuration with the sensor mounted in a refractory board (Case 2) with an incident radiant heat flux of $7.8 \mathrm{~kW} / \mathrm{m}^{2}$. 
TAB LE 1: Summary of experimental and theoretical results.

\begin{tabular}{|c|c|c|c|c|c|}
\hline & \multicolumn{5}{|c|}{ Con vective Heat Flux $\left(\mathrm{W} / \mathrm{m}^{2}\right)$} \\
\hline & Case 1 & & Case 2 & & \\
\hline$\overline{\bar{T}}$ & Exp. & $\overline{\text { Theory }}$ & Exp. & $T_{w}=250^{\circ} \mathrm{C}$ & $T_{w}=230^{\circ} \mathrm{C}$ \\
\hline $12^{\circ} \mathrm{C}$ & 175 & $\begin{array}{l}90- \\
240\end{array}$ & 1390 & 1420 & 1270 \\
\hline $46^{\circ} \mathrm{C}$ & 350 & $\begin{array}{l}160- \\
440\end{array}$ & 640 & 1000 & 860 \\
\hline
\end{tabular}

The second configuration (Case 2) yielded experimental heat fluxes of $1390 \mathrm{~W} / \mathrm{m}^{2}$ when $T_{c}=12^{\circ} \mathrm{C}$ and $640 \mathrm{~W} / \mathrm{m}^{2}$ for $T_{c}=46^{\circ} \mathrm{C}$. The results of the CFD calculations for this configuration, using either $T_{w}=250^{\circ} \mathrm{C}$ or $T_{w}=230^{\circ} \mathrm{C}$ were in acceptable agreement with these values taking all uncertainties into account. All the results are summarised in Table 1.

In evaluating the computed results one must bear mind the uncertainties in the interpretation of the experimental data, the uncertainties in the exact form of the heated element, the approximations introduced by assuming the gage to be quadratic ins tead of cylindrical and the assumption of constant thermal properties of air. Thus, the present calculations are only to be considered as preliminary. It is expected that the computed results can be considerably improved and that the error in the predictions can be reduced to at least below $20 \%$.

Despite the present difference between the experimental and theoretical results, the results indicate the feasibility of using CFD as a tool in estimating corrections for heat flux measurements obtained in a mixed heat flux environment. It is worth noting that even a $20 \%$ error in the heat transfer coefficient (or the convective heat flux) gives a far improved estimate of the measurements after correcting for the convective influence. If the convective error is say $20 \%$ of the total flux this means that the absolute error can be reduced to $4 \%$ by applying theoretically computed corrections.

\section{CON CLUDIN G REMARKS}

CFD calculations have been used to estimate the convective heat flux associated with Schmidt-Boelter measurements in two different experimental configurations. The results of these calculations have been favou rably compared to experimental results.

The calculations for both configurations studied were based on a series of assumptions about and estimates of experimental information that was not explicitly available. The ambient temperature was estimated to $T_{a}=24^{\circ} \mathrm{C}$, based on the solution of the two equations representing the heat balance for the two cooling water temperatures for the measurements using a sensor suspended in free air. The temperature of the sensors was determined assuming 32 junctions in the thermopile sensor. Finally, the temperature of the refractory board was approximated as $250^{\circ} \mathrm{C}$ based on experimental measurements at an incident heat flux of $8 \mathrm{~kW} / \mathrm{m}^{2}$. Calculations were also conducted using a temperature of $230^{\circ} \mathrm{C}$ to get an indication of the importance of the wall temperature.

Considering the uncertainty of these parameters, the agreement between the experiments and theory is sufficient to demonstrate the utility of CFD calculations in this application. Further work is necessary to increase the detail in the experimental information and to expand the number of configuration s that have been studied. 
In the specific case of the IMO surface flammability test for deck and bulkhead finish materials, Roberts on \& Ohlemiller [1] recommend that the flux meter be projected 10 $\mathrm{mm}$ from the specimen. Tests with a dummy specimen indicated that the convection error could be reduced from $14.6 \%$ to $5.4 \%$ in this way. It is interesting to note that by applying a theoretically calculated correction factor for the convection such an arrangement is unnecessary. If the convection can be calculated with an accuracy of $20 \%$, the absolute error in the measurements can be reduced to $3 \%$ with the meter still mounted flush with the surface. This error could be further reduced by measuring the surface temperature of the backing specimen and using that information as input to the CFD calculations.

Calculations of natural convection flows similar to those studied here, report an agreement of $14 \%$ between predicted and experimental results [6]. Thus, it is expected that the error in the calculated convective heat flux estimates of heat flux gages can be reduced to between 10 and $20 \%$ when introducing more accurate input data to the CFD model. Such data can be provided by complementary measurements of surface temperatures in the real experimental situations.

\section{REF ER EN CES}

1. Roberts on A.F. and Ohlemiller T.J., "Low Heat-flux Measurements: Some Precautions", Fire Safety Journal, 25, 109-124, 1995.

2. Ols son S., "Calibration of Radiant Heat Flux Meters - The Development of a Water Cooled Aperture for Use with Black Body Cavities", Swedish National Testing and Res earch Institute, SP Report 1991:58.

3. Olsson S. and Perss on B., "A New Method for Calibration of Heat Flux Meters", Proceedings of the Sixth International Fire Conference INTERFLAM '93. Inter science Communications Ltd, 1993.

4. Kuo C.H. and Kulkarni A.K., "Analys is of Heat Flux Measurement by Circular Foil Gages in a Mixed Convection/Radiation Environment", ASME/JSME Thermal Engineering Proceedings, Vol. 5, ASME 1991.

5. Rubini P.A., "SOFIE Technical Summary", School of Mechanical Engineering, Cranfield University, Internal report S-1996-1, 1996.

6. Abu-Mulaweh H.I., Armaly B.F. and Chen T.S., "Laminar Natural Convection Flow Over a Vertical Backward-Facing Step", Journal of Heat Transfer, 117, 895$901,1995$. 